\title{
PENGARUH SENAM KAKI DIABETES TERHADAP NILAI ANKLE BRACHIAL INDEX (ABI) DAN NILAI IPSWICH TOUCH TEST (IPTT) PADA PASIEN DM TIPE 2
}

\author{
Indhit Tri Utami* \\ Akper Dharma Wacana Metro \\ Email: indhitpribadi@yahoo.com
}

\begin{abstract}
Diabetes Melitus (DM) menyebabkan komplikasi yang dapat melibatkan vaskuler dan persarafan seperti oklusi arteri perifer dan neuropati. Penentuan sirkulasi perifer melalui pengukuran Ankle Brachial Index (ABI) merupakan metode invasif untuk memeriksa sirkulasi arteri perifer dan sebagai skrining terhadap adanya penyakit arteri oklusi perifer. Sementara itu, IpTT merupakan metode baru untuk mendeteksi penderita diabetes yang kehilangan sensasi kaki dan sebagai informasi untuk skrining adanya neuropati diabetes. Metode ini mudah, aman, cepat, dan mudah di lakukan dan diajarkan. Penelitian ini bertujuan untuk menilai apakah intervensi senam kaki dapat mempengaruhi Ankle Brachial Index (ABI) dan Nilai Ipswich Touch Test (IpTT) pada pasien DM Tipe 2. Rancangan penelitian menggunakan quasi ekspreriment pre post test design with control group. Pengambilan data menggunakan purposive sampling. Sampel pada penelitian ini terbagi menjadi kelompok intervensi $(n=18)$ dan kelompok kontrol $(n=18)$. Berdasarakan uji GLM - RM terdapat peningkatan nilai ABI dan IpTT pada kelompok intervensi sepanjang periode follow up (pre test, post test I, dan post test II). dengan $p$ value 0,000. Senam kaki diabetes dapat direkomendasikan sebagai intervensi mandiri keperawatan sebagai upaya pencegahan komplikasi gangguan vaskuler dan persarafan
\end{abstract}

\section{Kata kunci: Diabetes Melitus, Senam Kaki Diabetes, ABI, IpTT}

\section{LATAR BELAKANG}

Penyakit tidak menular adalah penyebab utama meningkatnya beban penyakit (disease burden) dan kematian di dunia, yang mana bertanggung jawab untuk sekitar 38 juta kematian pertahun, dari $68 \%$ total angka kematian di dunia (WHO, 2014). Sekitar 52\% kematian di bawah usia 70 tahun akibat penyakit tidak menular yang disebabkan oleh penyakit kardiovaskuler, kanker, Diabetes Melitus, dan penyakit pernapasan kronik (WHO, 2016). Indonesia berada pada region Asia - Pasifik, dimana peningkatan penyakit tidak menular secara signifikan ditemukan pada wilayah tersebut (Low, Lee \& Samy, 2014). Selain perubahan gaya hidup, urbanisasi dianggap sebagai faktor yang melatarbelakangi timbulnya penyakit tidak menular (Perkeni, 2015).

Secara global, jumlah penderita DM diperkirakan berjumlah 425 juta orang dan pada tahun 2045 diperkirakan jumlahnya akan meningkat menjadi 629 juta (International Diabetes Federation, 2017). Indonesia menempati peringkat keenam di dunia untuk prevalensi penderita DM setelah
China, India, Amerika Serikat, Brazil, dan Rusia, dengan jumlah 10,276,1 juta jiwa. Padahal sebelumnya data International Diabetes Federation (2015), posisi Indonesia menempati peringkat ketujuh di Dunia dengan jumlah 10 juta jiwa. Data dari Riskesdas tahun 2013, prevalensi Diabetes Melitus di Provinsi Lampung sebanyak 0.7\% (38.923 jiwa) dan Diabetes Melitus masuk ke dalam daftar sepuluh penyakit terbanyak pada pasien rawat jalan di puskesmas Kota Metro tahun 2015 dengan posisi kelima sejumah $(10 \%)$ dari semua total pasien rawat jalan (Profil Kesehatan Kota Metro, 2015).

Hiperglikemia pada Diabetes Melitus, terutama pada Diabetes tipe 2 menyebabkan komplikasi baik mikroangiopati dan makroangiopati (Black \& Hawks, 2014). Tingginya kadar gula darah dapat menyebabkan terjadinya komplikasi kronis yang mengakibatkan morbiditas yang cukup tinggi, salah satnya yaitu neuropati dan Penyakit Arteri Perifer. Prevalensi untuk terjadinya Neuropati Diabetes adalah sekitar $50 \%$ (Switlyk \& Smith, 2016). Afreen, et al (2017) menyatakan Neuropati Diabetes merupakan terbanyak ketiga gangguan kasus 
neurologi dengan kejadian 54\% dari 100.000 orang per tahunnya. Sementara kasus Penyakit Arteri Perifer (PAP) juga meningkat. Saat ini diperkirakan lebih dari 202 juta orang di dunia menderita PAP (Fowkes, 2013). Prevalensi PAP di Indonesia adalah sekitar 9,7\%. Resiko terjadinya PAP meningkat seiring dengan keparahan dan durasi diabetes, dimana mereka yang menderita DM memiliki kemungkinan $7-15$ kali lipat lebih tinggi (Ilminova, 2015) Komplikasi tersebut dikaitkan dengan gangguan mekanisme vaskular atau metabolik atau kedua - duanya.

Deteksi dini terhadap adanya gangguan sensasi perlu dilakukan dengan melakukan pemeriksaan neurologi. Pemeriksaan neurologi dalam hal ini pemeriksaan sensasi kaki salah satunya melalui Ipswich Touch Test yaitu merupakan metode baru yang sederhana dan tanpa alat untuk pemeriksaan neurosensori kaki diabetik. yang sederhana, cepat dilakukan, tanpa biaya, dan dapat dilakukan sebagai skrining neuropati diabetik. Selain gangguan sensori, penurunan sirkulasi ke perifer merupakan salah satu penyebab terjadinya Neuropati Diabetik, penyakit arteri perifer, dan Ulkus Diabetik pada Diabetes Melitus tipe 2 sebagai akibat adanya penurunan suplai oksigen dan nutrien (Clayton \& Elasy, 2009). Salah satu upaya untuk mengetahui adanya gangguan tersebut adalah dengan melakukan pemeriksaan Ankle Brachial Index (ABI)

Pencegahan terjadinya gangguan pada vaskularisasi perifer dan gangguan sensasi dalam pilar pengelolaan diabetes melitus merupakan bentuk tindakan non farmakologis. Terdapat beberapa tindakan non farmakologis untuk menegah terjadinya penyakit arteri perifer dan neuropati. Salah satunya ialah dalam bentuk exercise (Hinkle \& Cheever, 2014; Sogondo, dkk. 2009). Salah satu exercise yang yang direkomendasaikan adalah Senam Kaki Diabetes. Penelitian sebelumnya menyatakan adanya hubungan senam kaki dengan nilai ABI dan sensisitivitas kaki (Wahyuni, 2016; Priyanto, 2013)

Terjadinya komplikasi Diabetes Melitus melibatkan persarafan dan vaskuler seperti pada Neuropati ataupun Penyakit
Arteri Perifer merupakan rangkaian proses yang dinamis dan bergantung pada banyak faktor, maka pengelolaan atau pencegahan pada dasarnya merupakan bagian dari pengelolaan diabetes secara keseluruhan. Bentuk pencegahan atau pengelolaan ini diperlukan berbagai upaya khususnya pemahaman pentingnya pengkajian dan intervensi. Penelitian ini ingin melihat pengaruh senam kaki diabetes terhadap nilai Ankle Brachial Index (ABI) dan nilai Ipswich Touch Test (IpTT) pada pasien Diabetes Melitus tipe 2.

\section{METODE}

Penelitian ini menggunakan desain penelitian quasi ekspreriment pre post test design with control group. Peneliti menggunakan dua kelompok yaitu kelompok intervensi dan kelompok kontrol. Kelompok intervensi merupakan kelompok yang diberikan intervensi latihan Senam Kaki sedangkan kelompok kontrol tidak melakukan senam kaki.

Populasi dalam penelitian ini adalah semua pasien DM Tipe 2. Teknik sampling yang digunakan dalam penelitian ini yaitu purposive sampling atau pengambilan sampel dimana seluruh subjek yang memenuhi kriteria penelitian. Pemilihan sampel menggunakan rumus Federer, dimana jumlah sampel $\geq 16$. Namun peneliti menambahkan $10 \%$ sehingga jumlah sampel yang diambil sejumlah 18 responden untuk masing masing intervensi dan kontrol sehingga total 36 responden. Pada pengumpulan data sebelum dilakukan intervensi, pada kedua kelompok dilakukan pre - test, kemudian dilanjutkan pemberian intervensi latihan senam kaki diabetes pada kelompok intervensi. Setelah 3 kali senam kaki pada minggu ke - 1 diukur (post test I) dan kembali diukur setelah 3 kali senam kaki pada minggu ke - 2 (post test II). Pada kelompok kontrol diukur pada hari ke 6 dan ke 12. Instrumen pengukuran ABI menggunakan Simple Hand Held Vascular doppler ultrasound probe merek BT $200 \mathrm{~V}$ dan spignomanometer merek $\mathrm{ABN}$ yang telah terkalibrasi. Sementara pengukuran 
IpTT menggunakan prosedur dari Diaebetes UK 2017.

Analsis data dilakukan menggunakan statistik deskriptif digunakan untuk menggambarkan responden dan nilai $\mathrm{ABI}$ dan IpTT sebelum dilakukan intervensi. Statisik bivariat digunakan untuk mengetahui hubungan karakteristik responden dengan ABI dan IpTT serta melihat perbedaan rata rata ABI dan IpTT pada pre post, post test I, dan post test II. Sementara statistik multivariat digunakan untuk melihat pengaruh senam kaki diabetes terhadap nilai ABI dan IpTT dengan menggunakan uji statistik General Linier Multivariat Repeated Measure (GLM - RM). Data yang terkumpul diolah menggunakan perangkat lunak kamputer. Sebelum dilakukan uji bivariat terlebih dahulu dilakukan uji normalitas pada nilai ABI dan IpTT pada 3 waktu pengukuran, sehingga didapatkan $p$ value > 0,05 yang berarti berdistribusi normal dengan menggunakan uji Shapiro Wilk.

\section{HASIL}

\section{Analisis Univariat}

Tabel 1: Analisis perbedaan rata - rata nilai ABI dan IpTT $\left(\mathrm{T}_{1}, \mathrm{~T}_{2}\right.$, dan $\left.\mathrm{T}_{3}\right)$ antara kelompok intervensi dan kelompok kontrol $(n=36)$

\begin{tabular}{ccccccc}
\hline Variabel & $\begin{array}{c}\text { Waktu } \\
\text { Pengukuran }\end{array}$ & Kelompok & Mean & SD & f & P value \\
\hline \multirow{4}{*}{ ABI } & $\mathrm{T}_{1}$ & Intervensi & 0,79 & 0,09 & 0,37 & 0,54 \\
& & Kontrol & 0,77 & 0,09 & & \\
& $\mathrm{~T}_{2}$ & Intervensi & 0,85 & 0,07 & 7,89 & 0,01 \\
& & Kontrol & 0,77 & 0,09 & & \\
& $\mathrm{~T}_{3}$ & Intervensi & 0,95 & 0,07 & 31,36 & 0,00 \\
& & Kontrol & 0,79 & 0,09 & & \\
\hline \multirow{4}{*}{ IpTT } & $\mathrm{T}_{1}$ & Intervensi & 3,11 & 1,28 & 0,38 & 0,54 \\
& & Kontrol & 3,39 & 1,42 & & \\
& $\mathrm{~T}_{2}$ & Intervensi & 4,00 & 1,23 & 5,89 & 0,02 \\
& & Kontrol & 3,00 & 1,23 & & \\
& $\mathrm{~T}_{3}$ & Intervensi & 4,50 & 1,20 & 16,29 & 0,00 \\
& & Kontrol & 2,94 & 1,10 & & \\
\hline
\end{tabular}

Keterangan: $\mathrm{T}_{1}=$ pre test $; \mathrm{T}_{2}=$ post test $I ; \mathrm{T}_{3}=$ post test II

Tabel di atas menggambarkan perbedaan mean (rata - rata) nilai $\mathrm{ABI}$ dan IpTT pada 3 waktu pengukuran yaitu pre test, post test I, dan post test II antara kelompok intervensi dan kontrol. Hasil analisis dengan menggunakan Uji Oneway ANOVA diperoleh hasil bahwa ada peningkatan nilai ABI dan IpTT yang pada pengukuran post test $I$ (setelah 3 kali dilakukan senam kaki pada minggu ke -1) dan pada pengukuran post test II (setelah 3 kali senam kaki pada minggu ke -2). Dengan demikian H0 ditolak, artinya ada perbedaan nilai rata-rata $\mathrm{ABI}$ dan IpTT antara kelompok intervensi dan kelompok kontrol $(p=0,000)$

Tabel 2: Pengaruh senam kaki diabetes terhadap nilai $A B I$ pada $T_{1}, T_{2}$, dan $\mathrm{T}_{3}$

\begin{tabular}{ccccc}
\hline Kelompok & $\begin{array}{c}\text { Perubahan nilai } \\
\text { ABI }\end{array}$ & $\begin{array}{c}\text { Selisih } \\
\text { Rerata }\end{array}$ & SE & P value \\
& $\mathrm{T}_{1}-\mathrm{T}_{2}$ & $-0,06$ & 0,01 & \\
Intervensi & $\mathrm{T}_{1}-\mathrm{T}_{3}$ & $-0,15$ & 0,02 & 0,000 \\
& $\mathrm{~T}_{2}-\mathrm{T}_{3}$ & $-0,09$ & 0,02 & \\
\hline \multirow{3}{*}{ Kontrol } & $\mathrm{T}_{1}-\mathrm{T}_{2}$ & $-0,00$ & 0,01 & \\
& $\mathrm{~T}_{1}-\mathrm{T}_{3}$ & $-0,02$ & 0,02 & 0,539 \\
& $\mathrm{~T}_{2}-\mathrm{T}_{3}$ & $-0,02$ & 0,02 & \\
\hline
\end{tabular}

Keterangan : $\left(\mathrm{T}_{1}=\right.$ pre test $; \mathrm{T}_{2}=$ minggu ke -1 (post test $\left.I\right)$; $\mathrm{T}_{3}=$ minggu ke -2 (post test II)

Berdasarkan analisis utama terdiri dari 2 kelompok (intervensi vs kontrol) x 3 (waktu: Time 1, Time 2, Time 3). Hasil ini mendukung hipotesis bahwa pasien DM yang mendapatkan intervensi senam kaki mempunyai nilai $\mathrm{ABI}$ yang lebih tinggi dibandingkan dengan yang tidak mendapatkan intervensi.. Hal ini mengindikasikan bahwa terjadi peningkatan nilai ABI baik pada kelompok intervensi maupun pada kelompok kontrol sepanjang periode follow - up $\left(\mathrm{T}_{1}, \mathrm{~T} 2\right.$, dan $\left.\mathrm{T}_{3}\right)$ dengan $p$ value 0,000 .

Tabel 3: Pengaruh senam kaki diabetes terhadap nilai IpTT pada $\mathrm{T}_{1}, \mathrm{~T}_{2}$, dan $\mathrm{T}_{3}$

\begin{tabular}{ccccc}
\hline Kelompok & $\begin{array}{c}\text { Perubahan nilai } \\
\text { IpTT }\end{array}$ & $\begin{array}{c}\text { Selish } \\
\text { Rerata }\end{array}$ & SE & Pvalue \\
\hline \multirow{3}{*}{ Intervensi } & $\mathrm{T}_{1}-\mathrm{T}_{2}$ & $-0,89$ & 0,19 & \\
& $\mathrm{~T}_{1}-\mathrm{T}_{3}$ & $-1,39$ & 0,22 & 0,000 \\
& $\mathrm{~T}_{2}-\mathrm{T}_{3}$ & $-0,50$ & 0,18 & \\
\hline \multirow{3}{*}{ Kontrol } & $\mathrm{T}_{1}-\mathrm{T}_{2}$ & 0,39 & 0,19 & \\
& $\mathrm{~T}_{1}-\mathrm{T}_{3}$ & 0,44 & 0,22 & 0,096 \\
& $\mathrm{~T}_{2}-\mathrm{T}_{3}$ & 0,06 & 0,18 & \\
\hline
\end{tabular}

Keterangan : $\left(\mathrm{T}_{1}=\right.$ pre test $; \mathrm{T}_{2}=$ minggu ke -1 (post test $\left.I\right)$; $\mathrm{T}_{3}=$ minggu ke -2 (post test II) 
Penelitian ini juga untuk mengetahui pengaruh senam kaki diabetes terhadap nilai Ipswich Touch Test (IpTT). Hasil ini mendukung hipotesis bahwa pasien DM yang mendapatkan intervensi senam kaki mempunyai nilai IpTT yang lebih tinggi dibandingkan dengan yang tidak mendapatkan intervensi. Hal ini mengindikasikan bahwa terjadi peningkatan nilai IpTT baik pada kelompok intervensi maupun pada kelompok kontrol sepanjang periode follow - up $\left(T_{1}, T 2\right.$, dan $\left.T_{3}\right)$. Perubahan nilai IpTT dalam kelompok intervensi antar waktu pengukuran ditemukan signifikansi secara statistik $p$ value 0,000 .

\section{PEMBAHASAN}

\section{Pengaruh Senam Kaki Diabetes terhadap Ankle Brachial Index}

Senam kaki (diabetic foot care) dapat memperbaiki sirkulasi darah dan memperkuat otot - otot kecil, seperti meningkatkan kekuatan otot betis dan otot paha (Sugondo, dkk., 2009). Salah satu gerakan dalam senam kaki ialah dorsofleksi dan plantar fleksi. (otot - otot tungkai).

Ketika terjadi pergerakan tungkai, akan mengakibatkan menegangnya otot-otot tungkai dan menekan vena di sekitar otot tersebut. Hal ini akan mendorong darah kearah jantung dan tekanan vena akan menurun, mekanisme ini dikenal dengan pompa vena. Mekanisme ini akan membantu memperlancarkan peredaran darah bagian kaki dan memperbaiki sirkulasi darah.

Peredaran darah yang lancar menghambat proses penebalan dari membran kapiler, peningkatan ukuran dan jumlah sel endotel kapiler, sehingga diameter lumen pembuluh darah tetap adekuat khususnya pembuluh darah kapiler. Oleh karena itu, terjadi perbaikan nilai tekanan darah sistolik baik brachial maupun ankle. Penelitian oleh Subekti (2017) senam kaki berpengaruh terhadap peningkatan nilai ABI dari 0,72 \pm 0,09 menjadi $0,82 \pm 0,08$ dengan $p$ value 0,001 .

\section{Pengaruh Senam Kaki Diabetes terhadap Ipswich Touch Test (IpTT)}

Pergerakan senam kaki memperbaki sirkulasi darah dan memperbaiki fungsi endotelium pembuluh darah sehingga produksi Nitric Oxide sebagai vasodilator akan memperbaiki sirkulasi darah. Selain itu olahraga dapat meningkatkan Vascular Endothelial Growth Factor (VEGF) pada dalam jumlah cukup di otot untuk meningkatkan vaskularisasinya (Guyton \& Hall, 2011).

Peningkatan VEGF menghasilkan peningkatan densitas kapiler dan memperbaiki sirkulasi darah perifer. Keadaan ini membantu mencegah iskemia syaraf dan memperbaiki gangguan sensasi pada pasien DM (Groover, 2014 dalam Darmayan, 2016). Latihan fisik meningkatkan fungsi kardiovaskuler dan vasodilator endotel yang memiliki keuntungan untuk meningkatkan produksi NO sehingga meningkatkan vasodilatasi vaskular yang berdampak terhadap sirkulasi ke bagian saraf (Bernando, Bryk, \& Fucs, 2015).

Penelitian serupa yang dilakukan oleh Priyanto (2013) menunjukkan ada perbedaan secara bermakna rata-rata sensitivitas kaki sebelum dilakukan senam kaki dengan sensitivitas kaki sesudah dilakukan senam kaki dengan p value 0,000 .

\section{KESIMPULAN}

Pada penelitian ini terdapat perbedaan signifikan nilai ABI dan IpTT pada pengukuran minggu ke -1 (post test I) dan minggu ke -2 (post test II) antara kelompok intervensi dengan kelompok kontrol. Karakteristik responden meliputi usia, lama menderita DM, riwayat hipertensi, dan riwayat merokok memiliki hubungan terhadap ABI dan IpTT. Senam kaki diabetes mellitus berpengaruh terhadap perubahan nilai ABI bahwa pasien DM yang mendapat senam kaki mempunyai nilai ABI dan IpTT yang lebih tinggi dibandingkan dengan yang tidak mendapat senam kaki. Penelitian ini akan merubah paradigma ilmu keperawatan dari direct care menuju preventive dan promotif care dalam keilmuan keperawatan 
medikal bedah. Melalui hasil penelitian inileh karena itu, perlunya melakukan exercise seperti senam kaki diabetes dan juga perlunya menilai ABI dan IpTT secara berkala pada penderita Diabetes Melitus sehingga terhindar dari komplikasi untuk menurunkan angka morbiditas dan mortalitias.

\section{DAFTAR PUSTAKA}

Afreen, S.,et al. (2017). Prevalence of Sensory Peripheral Neuropathy in Diabetic Patients at Diabetes Care Centre: a cross sectional study DOI: www.msjonline.org/index.php/ijrms/art icle/.../3705/3311

Bernardo, D. N. D., Bryk, F. F., \& Fucs, P. M. de M. B. (2015). Influence of nitric oxide in the improvement of muscle power. Acta Ortopedica Brasileira, 23(6), 294-298. http://doi.org/10.1590/ 1413-785220152306148249

Black, J.M. \& Hawks, J.H. (2014). Keperawatan Medikal Bedah Manajemen Klinis Untuk Hasil yang di harapkan Edisi 8. Singapura: Elseiver.

Clayton, W. \& Elasy, T.A. (2009). A Review of The Pathophysiology, Cassification and Treatment of Foot Ulcer in Diabetic Patient. https://pdfs. semanticscholar.org/7fde/15821fb6490 65d1ae6c1637fde5252c6606a.pdf

Darmayan. (2016). Pengaruh Akupressure dan Fot Exercise Terhadap Nilai ABI. Tesis.

Fowkes, F.G. (2013). Comparison of global estimates of prevalence and risk factors for peripheral artery disease in 2000 and 2010: a systematic review an analysis. Dec; 75 (12):783. www.ncbi.nlm.nih.gov

PMID 23915883.

Guyton \& Hall. (2011). Buku Ajar Fisiologi Kedokteran Edisi Kedua belas. Singapura: Saunders Elseiver.
Hinkle \& Cheever.(2014). Brunner \& Suddarth's Textbook of MedikalSurgical Nursing 13 th Edition. Wolters Kluwer: Lippincott Williams \& Wilkins.

Ilminova.,et al.(2015). Hubungan antara status diabetes melitus dengan status penyakit arteri perifer (PAP) pada pasien hipertensi. http://onesearch.id/Record/IOS2852.46 704?widget $=1$ \&institution_id=67

International Diabetes Federation. (2015). IDF Diabetes Atlas 7th Edition. http://www.oedg.at/pdf/1606_IDF_Atla s_2015_UK.pdf.

International Diabetes Federation. (2017). IDF Diabetes Atlas 8th Edition. http://www.diabetesatlas.org/resources/ 2017-atlas.html.

Low, W.Y., Lee, Y.K., Samy, A.L. (2014). Non-communicable diseases in the Asia-Pacific region: Prevalence, risk factors and community-based prevention 2015;28(1):20-6 https://www.ncbi.nlm.nih.gov/pubmed/ 26159943.

Perkeni. (2015) Konsesus Pengelolaan dan Pencegahan Diabetes Melitus tipe 2 di Indonesia.

pbperkeni.or.id/doc/konsensus.pdf. d

Priyanto. (2013). Pengaruh Senam Kaki Terhadap Sensitivitas Kaki dan Kadar Gula Darah Pada Aggregate Lansia Diabetes Melitus di Magelang. Skripsi.http://jurnal.unimus.ac.id/index. php/psn12012010/article/download/853 1907.

Profil Kesehatan Kota Metro. (2015). dinkes.metrokota.go.id/downlot.php?fil e=profil_dinkes_2015.pdf.

Kemenkes RI. (2014). Laporan Riskesdas 2013. www.depkes.go.id/resources/ download/general/Hasil\%20Riskesdas $\% 202013 . p d f$.

Subekti, A.S. (2017). Pengaruh Senam Kaki Terhadap sirkulasi Perifer Dilihat dari Nilai Ankle Brachial Index Pada Pasien Diabetes Melitus Di RSUD Dr. Moewardi. http://digilib.stikeskusuma husada.ac.id/files/disk1/34/01-gdlatiksrisub-1653-1-artikel-h.pdf. 
Sugondo, dkk. (2009). Penatalaksanaan Diabetes Melitus Terpadu. Jakarta: Fakultas Kedokteran UI.

Switlyk, K. J \& Smith, G. (2016). Updates in diabetic peripheral neuropathy [version 1; referees: 3 approved]. https://www.ncbi.nlm.nih.gov/pmc/arti cles/PMC4847561/.

Wahyuni, A. (2016). Senam Kaki Diabetes Efektif meningkatkan Ankle Brachial Index Pasien DM Tipe 2. Skripsi.
World Health Organization. (2014). STEP wise approach to chronic disease risk factor surveillance (STEPS). Geneva: WHO; 2014 [cited 2014 Mar 20]. Available from: http://www.who.int/chp/steps/riskfactor len.

World Health Organization. (2016). Global Status Report on non comunicable disease 2015. Geneva: WHO 2015. 